\title{
Consumption of Sun-Exposed Oyster Mushrooms Help Patients Fight Tuberculosis
}

\author{
Tibebeselassie Seyoum Keflie, MPhil, Ph.D. ${ }^{\star}$, Aregash Samuel, Ph.D. ${ }^{2}$, Ashagrie Zewdu Woldegiorgis, Ph.D. ${ }^{3}$, \\ Christine Lambert, Ph.D. ${ }^{4}$, Donatus Nohr Ph.D. ${ }^{4}$, Hans Konrad Biesalski, MD, Ph.D. ${ }^{4}$ \\ ${ }^{1} 70599$ Stuttgart. Former at Institute of Nutritional Science, University of Hohenheim, Stuttgart, Germany. \\ ${ }^{2}$ Ethiopian Public Health Institute, Addis Abeba, Ethiopia \\ ${ }^{3}$ Centre for Food Science and Nutrition, College of Natural Sciences, Addis Ababa University, Addis Abeba, Ethiopia \\ ${ }^{4}$ Institute of Nutritional Science, University of Hohenheim, Stuttgart, Germany
}

\begin{abstract}
Asian Journal of Complementary and Alternative Medicine. Volume 09 Issue 2
\end{abstract}
Published on: 18/05/2021

*Author for Correspondence: Dr. Tibebeselassie Seyoum Keflie. 70599 Stuttgart, Germany. Former at Institute of Nutritional Science, University of Hohenheim, Stuttgart, Germany; E-Mail: tibebe.fscuhoh@gmail.com; Tel: +4917658995469

Cite this article as: Keflie TS, Samuel A, Woldegiorgis AZ, Lambert C, Nohr D, et al. Consumption of Sun-Exposed Oyster Mushrooms Help Patients Fight Tuberculosis. Asian Journal of Complementary and Alternative Medicine, Vol 9(2), 32-41:2021.

\begin{abstract}
Introduction: Tuberculosis (TB) is an airborne infectious disease that usually affects the lungs leading to severe coughing, fever, and chest pains.
\end{abstract}

Objective: This study aimed to assess the effects of consuming sun-exposed mushrooms on the treatment outcomes of TB

Methods: Participants were TB patients and categorized into block-1 (32) and block-2 (32) based on their willingness to consume sandwich bread containing sun-exposed oyster mushrooms. Blood and sputum samples were taken at the beginning (Day 0) and end of the study ( $4^{\text {th }}$ month). Assays of 25-hydroxy $(\mathrm{OH})$ D, cytokines, LL-37, and CRP were performed using Enzyme LinkedImmunosorbent Assay (ELISA) technique, and mycobacterial cultures were performed using Löwenstein Jensen media. A p-value less than 0.05 was considered significant.

Results: Consumption of the sandwich bread induced a $27.8 \%$ increase in the mean serum $25(\mathrm{OH}) \mathrm{D}$ level with $35.5 \%$ and $32.3 \%$ reduction in the proportion of vitamin D deficiency (VDD) and insufficiency (VDI), respectively. There were progressive changes in TB score (mean \pm SD of $2.6 \pm 1.8 ; 95 \%$ CI of 1.95 to $3.17 ; \mathrm{p}<0.001)$ and Karnofsky performance status scale $(80.3 \pm 6.9 \%, \mathrm{p}<$ $0.001)$ with significant improvements in IFN $-\gamma$ and LL-37 levels $(\mathrm{p}<0.05)$.

Conclusion: Consumption of sun-exposed oyster mushrooms effectively improved the deficiencies of vitamin D in TB patients. The accelerated improvements on the clinical and immunological outcomes give us a clue that sun-exposed oyster mushrooms could serve as a potential, safe, easily available, and affordable adjunctive treatment and help patients fight TB.

Keywords: Sun-exposure; Mushrooms; Vitamin D; Tuberculosis; Treatment outcomes

Abbreviations: $25(\mathrm{OH}) \mathrm{D}=25$-hydroxy vitamin $\mathrm{D} ; \mathrm{AFB}=$ Acid Fast Bacilli; ELISA = Enzyme Linked Immunosorbent Assay; $\mathrm{TB}=$ Tuberculosis; UVB = Ultra Violet $\mathrm{B}$; VDD = Vitamin D Deficiency.

\section{INTRODUCTION}

Tuberculosis (TB) is an airborne infectious disease caused by Mycobacterium tuberculosis that usually affects the lungs leading to severe coughing, fever, and chest pains [1-3]. Studies done until the recent time provided valuable insight into TB transmission, diagnosis, and treatment. However, much remains to be discovered to effectively reduce the incidence and eventually eradicate TB $[4,5]$. TB has a relationship with vitamin D. A meta-analysis found that low serum vitamin D status was associated ith an increased risk of TB [6]. In the pre-antibiotic era, vitamin D was used to treat TB. The use of Vitamin D for TB treatment started in 1849 , with the observation that oil from fish liver improved appetite and strength [7]. The major circulating metabolite of vitamin D, 1,25-dihydroxyvitamin D $\left(1,25[\mathrm{OH}]_{2} \mathrm{D}\right)$, supports innate antimicrobial immune responses, suggesting a potential mechanism by which adjunctive vitamin D might enhance response to anti-TB therapy [8]. 
Mushrooms are the only non-animal food source that contains vitamin D [9]. Ergosterol is the principal sterol and precursor for vitamin $\mathrm{D}_{2}$ in mushrooms. It is converted via absorption of ultraviolet B (UVB) light energy (290-320 nm). The absorption of light causes the isomerization of the molecule and bond cleavage between carbons 9 and 10, resulting in unstable intermediate "pre-vitamin $\mathrm{D}_{2}$ ". The conversion of pre-vitamin $\mathrm{D}_{2}$ to vitamin $\mathrm{D}_{2}$ then follows via a thermally catalyzed process $[10,11]$.

Commercially cultivated mushrooms contain low amounts of vitamin $\mathrm{D}_{2}[12,13]$. Some commercial producers include UVB radiation steps to increase the content of vitamin $D_{2}$ in their products $[14,15]$. Sun-exposure produced a sufficient amount of vitamin $\mathrm{D}_{2}$ in mushrooms. Our previous study revealed that sun-exposed oyster mushroom is an excellent resource of vitamin D which is comparable to the content of vitamin $\mathrm{D}_{3}$ in cod liver oil [16]. Having this, we hypothesized that sun-exposed mushroom has an impact on TB. Therefore, the present study aimed to assess the effects of consuming sunexposed oyster mushrooms on the treatment outcomes of TB.

\section{METHODS}

\section{Study site and design}

The study was performed in the central part of Ethiopia from December 2014 to June 2015. Participants were TB patients and categorized into two blocks based on their willingness to consume sandwich bread containing sun-exposed oyster mushrooms.

\section{Sun-exposure of oyster mushroom}

Sun-exposure improves the content of vitamin $\mathrm{D}_{2}$ in oyster mushrooms (Pleurotus ostreatus) [16]. Fresh oyster mushrooms were procured from Bio-Enguday Production and Sale Micro-enterprise (Debre Birhan, Ethiopia) with a moisture content of $92.5 \%$ as determined by the oven drying method. To facilitate the production of vitamin $\mathrm{D}_{2}$, mushrooms were chopped down to the volume of $9 \mathrm{~cm}^{3}(3 \mathrm{~cm} \mathrm{x} 3 \mathrm{~cm} \mathrm{x}$ $1 \mathrm{~cm}$ ) and exposed to the sunlight for 3 hours. Immediately after sun-exposure, mushrooms were put into a plastic bag and kept at $-20^{\circ} \mathrm{C}$. The detailed process of Sun-exposure was described in our previous work [16].

\section{Vitamin $D_{2}$ analysis}

Samples were taken, packed into insulated plastic bags together with dry ice, and transported to the University of Hohenheim (Stuttgart, Germany) where further analysis of vitamin $\mathrm{D}_{2}$ was done. The extraction of vitamin $\mathrm{D}_{2}$ was performed based on the method indicated in Keflie et al. [16]. A system of HighPerformance Liquid Chromatography (HPLC) (Shimadzu technologies) equipped with a DGU-20A3R degassing Unit, two LC-20AT pumps, a SIL-20ACHT autosampler, and a CBM-20A communication bus module (Shimadzu GmbH, Duisburg, Germany) as well as Reprosil 80 ODS-2 analytical column, $4.6 \times 250 \mathrm{~mm}, 3 \mu \mathrm{m}$ particle size (Dr. Maisch $\mathrm{GmbH}$, Ammerbuch, Germany) was used to measure vitamin $\mathrm{D}_{2}$ at Institute of Biological Chemistry and Nutrition. Our pre-test experiment on the effect of cooking temperature indicated that vitamin $\mathrm{D}_{2}$ was almost stable during the process of cooking (Data not shown).

\section{Sandwich bread preparation}

Sandwich bread was prepared everyday morning using ingredients of sun-exposed oyster mushroom, wheat bread, olive oil, onion, and salt. We used $27 \mathrm{~g}$ of sun-exposed oyster mushroom (containing $146 \mu \mathrm{g}$ of $\mathrm{VD}_{2}$ ) to prepare one sandwich bread.

\section{Inclusion and exclusion criteria}

Eligibility assessment was performed at health facilities. The major inclusion criteria were: newly diagnosed, smear-positive, and active pulmonary TB. Patients with extrapulmonary TB, multi-drug resistant TB, HIV infection, chronic diseases, or taking immunosuppressive drugs, or vitamin D supplementation were excluded.

\section{Follow-up and data collection}

All patients were attending a directly observed treatment short-course (DOTS) programme and received anti-TB drugs. Follow-up continued for 4 months. Patients who showed their willingness to consume the sandwich bread (Block-1) were provided with the sandwich for 5 days in a week for 16 weeks. Adherence to the DOTS programme and consumption of mushroom sandwich bread were supervised by the clinical nurses. Patients were checked every week for any kind of complaints and undergone physical examination.

Socio-demographic data were collected using a pre-tested and structured questionnaire which is translated to Amharic (local language). Medical records were also used to collect clinical characteristics. Vitamin D intake was assessed using a modified food frequency questionnaire (FFQ). The questionnaire included the availability of vitamin D-rich foods, monthly income, money spent for foods, duration of sun-exposure, working hours in the sun, clothing style, and use of sun protection. The types of all market and traditional foods were completely listed and, self-administered supplementary vitamin D intake was also considered in the assessment of dietary intake.

\section{Samples collection}

Blood and sputum samples were taken at the beginning (Day 0 ) and end of the study ( $4^{\text {th }}$ month). After overnight fasting, 10 
$\mathrm{mL}$ of venous blood was withdrawn from the antecubital fossa vein into a non-heparinized vacutainer tube between 8:00 and 10:00 am at all health facilities. Blood samples were allowed to clot for about $1 \mathrm{~h}$ in the dark and subjected to centrifugation at $2504 \mathrm{xg}$ for $10 \mathrm{~min}$ at room temperature.

Samples with visible haemolysis were discarded. The sera were separated immediately into aliquots of sterile Eppendorf tubes using sterile Pasteur pipettes and stored at $-20{ }^{\circ} \mathrm{C}$. Later, the sera were transported in the icebox to Armauer Hansen Research Institute (AHRI) in Addis Abeba, Ethiopia, where they were stored at $-80{ }^{\circ} \mathrm{C}$ until the time of analysis. We used the sera for the analyses of $25(\mathrm{OH}) \mathrm{D}$, cytokines, cathelicidin (LL-37), and C-Reactive Protein (CRP). Similarly, early morning sputum specimens were collected in a sterile plastic cap for AFB (Acid Fast Bacilli) smear examination and mycobacterial culture. Sputum specimens were stored at -20 ${ }^{\circ} \mathrm{C}$ and later transported in the icebox to AHRI.

\section{Laboratory analyses}

25 hydroxy $(\mathbf{O H})$ vitamin D: Serum $25(\mathrm{OH}) \mathrm{D}$ (vitamin $\mathrm{D}_{2}$ plus $\mathrm{D}_{3}$ ) levels were assayed in duplicate using an EnzymeLinked Immunosorbent Assay (ELISA) kit purchased from Enzo Life Sciences, GmbH (Lörrach, Germany). The assay was done as per the manufactureres instructions. The kit had $1.98 \mathrm{ng} / \mathrm{mL}$ detection limits with a 0.5 to $1010 \mathrm{ng} / \mathrm{mL}$ assay range. Measurements were categorized as severe vitamin $\mathrm{D}$ deficiency (sVDD) $(\leq 10 \mathrm{ng} / \mathrm{mL})$, deficiency (VDD) $(\leq 20$ $\mathrm{ng} / \mathrm{mL})$, insufficiency (VDI) $(\leq 30 \mathrm{ng} / \mathrm{mL})$ and sufficiency (adequate level) (VDS) $(>30 \mathrm{ng} / \mathrm{mL})[17,18]$.

Cytokines, Cathelicidin (LL-37), and C-Reactive Protein (CRP): Levels of IFN- $\gamma$, Interleukin-4 (IL-4), IL-10, LL-37, and CRP in the serum were measured using ELISA kits. The kits for IFN- $\gamma$ and IL-4 were purchased from Sigma-Aldrich (Saint Louis, MO63103 USA) with detection limits of 15 pg/ $\mathrm{mL}$ and $5 \mathrm{pg} / \mathrm{mL}$, respectively. The kit for IL-10 was purchased from Enzo Life Sciences, GmbH (Lörrach, Germany). This kit had a detection limit of $<7.81 \mathrm{pg} / \mathrm{mL}$. Likewise, the kits of LL37 and CRP were purchased from Hycult GmbH (Beutelsbach, Germany) and their detection limits were $0.1 \mathrm{ng} / \mathrm{mL}$ and $<5$ $\mathrm{ng} / \mathrm{mL}$, respectively. The Mean value of CRP $\geq 10 \mu \mathrm{g} / \mathrm{mL}$ was considered as a positive indicator of infection or inflammation. The assays were carried out as per the manufactureres instructions.

Acid Fast Bacilli smear examination and Culture: Duplicated sputum specimens were collected from each patient. AFB smears were prepared using the Ziehl-Neelsen staining technique as previously described in Keflie and Ameni [19]. AFB smears were denoted as $+1,+2,+3$, and +4 whenever 1-9 AFB in 100 high-powered fields, 1-9 AFB in 10 high-powered fields, 1-9 AFB in 1 high powered field, or $>9$ AFB in 1 high powered field were observed, respectively [20].

Sputum specimens were decontaminated with $4 \%$ sterile $\mathrm{NaOH}$ solutions and culture was performed using LöwensteinJensen solid media as previously indicated in Keflie and Ameni [19]. Bacterial cultures were monitored for 6 to 8 weeks until colonies were detected.

\section{Anthropometry}

Anthropometric measurements such as body weight, height, and mid-upper arm circumference (MUAC) were obtained using standardized procedures. All patients were weighed while wearing light clothes using an electronic platform weighing scale to the nearest $0.1 \mathrm{~kg}$. Height was measured to the nearest $0.1 \mathrm{~cm}$ using a Seca stadiometer. Body mass index (BMI) was calculated as body weight $(\mathrm{kg})$ divided by height (m) squared $\left(\mathrm{kg} / \mathrm{m}^{2}\right)$. BMI values of $18.5,17.0$, and $16.0 \mathrm{~kg} /$ $\mathrm{m}^{2}$ were used as the cut-off values below which patients were classified as having mild, moderate, or severe malnutrition, respectively [21]. MUAC was measured halfway between the olecranon and acromion processes of the left arm using a flexible non-stretch measuring tape to the nearest $0.1 \mathrm{~cm}$ while the arm is hanging relaxed, without compressing the tissues. MUAC less than $23 \mathrm{~cm}$ for males and $22 \mathrm{~cm}$ for females are used to define undernutrition as per FANTA III [22].

\section{Outcomes}

The primary outcomes were changes in vitamin D status, clinical improvements, and immunologic responses. Clinical outcomes were assessed using TB score and Karnofsky performance status scale. TB score measures change in the clinical status of TB patients and its components include self-reported symptoms (cough, dyspnoea, night sweat, chest pain, haemoptysis), clinical signs (tachycardia, pallor, fever, auscultatory findings), BMI (Low BMI: $\leq 18.5 \mathrm{~kg} / \mathrm{m}^{2},<16 \mathrm{~kg}$ / $\left.\mathrm{m}^{2}\right)$ and MUAC $(<23 \mathrm{~cm}$ for male or $<22 \mathrm{~cm}$ for female, $<$ $20 \mathrm{~cm}$ ). Each variable contributed 1 point and the total score varies from 0 to 13 points. The score was grouped as mild (Severity Classes (SC)-I: 0-5 points), moderate (SC-II: 6-7 points), or severe (SC-III: 8 points and more). A low TB score correlates with favourable outcomes, cure, and completed treatment [23]. Likewise, Karnofsky performance status scale correlates purely to physical ability and covers 11 points, each scored as a percentage from normal health to death (100 to $0 \%$ ) [24]. Sputum smear conversion and culture negativity were evaluated as the secondary outcome.

\section{Adverse effects}

Patients were interviewed for the occurrence of adverse events related to hypercalcemia such as nausea, vomiting, excessive 
thirst, anorexia, symptoms of kidney stones, and confusion. In addition, the occurrence of itching, arthralgia, jaundice, headache, malaise, dyspepsia, and others were asked.

\section{Ethics}

This study was undertaken in accordance with Helsinki declaration and approved by the Ethics Review Committee of AHRI-ALERT(AllAfrica Leprosy Rehabilitation and Training) as part of the project entitled " Effect of micronutrients on the treatment outcomes of TB ${ }^{\text {eee }}$ (Project Reg. No. P057/14). Written informed consent was obtained from the patients after explaining the aim and purpose of the study. All concerned health bureau of North Shewa Zone of Amhara Regional State gave supports and facilitated the processes of the present study.

\section{Statistical analysis}

Sample size estimation was done based on the previous findings of TB Score reduction after 2 months of anti-TB treatment with the mean $\pm \mathrm{SD}$ of $3.2 \pm 2.3$ [23]. With the assumption of a $36 \%$ more reduction in the primary clinical TB score after vitamin $\mathrm{D}_{2}$ intervention at a $5 \%$ level of significance, $80 \%$ power, and $10 \%$ dropout rate, the sample size was calculated to be 34 for each group with a total of 68 patients. The study was analyzed using IBM SPSS version 23 statistical program and data were summarized as mean $\pm \mathrm{SD}$ or median with IQR (Inter Quartile Range) for continuous variables and frequencies with percentages for categorical variables. Means were compared using a two-tailed paired t-test or Wilcoxon signed-rank sum test depending on the results of the Shapiro-Wilk test for normality of distribution.

The differences in the proportions were analyzed using Chisquare $\left(\mathrm{X}^{2}\right)$ or Fisheres $\mathrm{s}$ exact test (when more than $20 \%$ of the cells have expected count less than 5). Kruskal-Wallis test was applied to assess the changes in the serum $25(\mathrm{OH})$ D levels across different categorical variables. Pearson ${ }^{\text {ee }}$ s and Spearman correlation tests were used to identify the associations between parametric and non-parametric variables, respectively. Variables with a p-value less than 0.25 in bivariate analysis were entered into a multiple linear regression model to evaluate the relationship between the changes in the serum 25(OH)D levels and the clinical outcomes by adjusting independent factors. A p-value less than 0.05 was considered statistically significant.

\section{RESULTS}

A total of 64 patients ( 32 patients assigned in block-1 and 32 patients assigned in block-2) completed the study. Basic characteristics were compared between block-1 and 2. As it is indicated in Table 1, the two blocks had almost similar baseline characteristics. The median age with IQR was $28(14)$ years in block-1 and $26(8.5)$ years in block-2.

\section{Sun-exposed oyster mushroom}

The content of vitamin $\mathrm{D}_{2}$ in fresh oyster mushroom was almost nil. However, a large amount of vitamin $\mathrm{D}_{2}$ was produced after Sun-exposure and we obtained concentrations of $540.9 \mu \mathrm{g} /$ $100 \mathrm{~g}$ fresh weight.

\section{Vitamin D}

More than $65 \%$ of the study participants spent 30 to $50 \%$ of their monthly income on food. But, less than $26 \%$ of them tried to include vitamin D-rich foods like oily fish in their diet. The correlation between the serum $25(\mathrm{OH}) \mathrm{D}$ level and vitamin D-rich food intake, working in the sun for 1 hour per day, use of sun protection, and clothing style were not significant. Although more than $40 \%$ of TB patients were working in the sun for about 1 hour per day, their skin did not directly expose to the sunlight as most of them ( $>68 \%$ ) cover their bodies with clothes and using sun protection like an umbrella (Table 1).

The mean \pm SD of serum $25(\mathrm{OH}) \mathrm{D}$ level at baseline was $29.1 \pm 12.3 \mathrm{ng} / \mathrm{mL}$ versus $30.6 \pm 16.8 \mathrm{ng} / \mathrm{mL}$ in block- 1 and 2 , respectively. The proportions of VDD and VDI at baseline were nearly $42 \%$ and $58 \%$ in block- 1 and about $41 \%$ and $59 \%$ in block-2 (Table 2). After 4 months, the mean serum $25(\mathrm{OH})$ D level was higher in block-1 than block-2. Consumption of the sandwich bread induced a $27.8 \%$ increase in the mean serum $25(\mathrm{OH}) \mathrm{D}$ level in block-1 (for the difference: mean \pm SD of $8.1 \pm 6.2 \mathrm{ng} / \mathrm{mL} ; 95 \%$ CI of 5.9 to $10.3 \mathrm{ng} /$ $\mathrm{mL}, \mathrm{p}<0.001$ ) (Figure 1). The proportions of VDD and VDI were significantly reduced in block-1 by $35.5 \%$ and $32.3 \%$, respectively. Although the reduction was not statistically significant, the corresponding values were $17.3 \%$ and $6.9 \%$ in block-2 (Table 2). The changes in the serum 25(OH)D level were not significantly different across sex and age categories.

\section{Clinical outcomes}

At baseline, block-1 and 2 had the mean \pm SD of TB score of $6.1 \pm 3.2$ and $6.9 \pm 2.1$ points, espectively. About $34 \%$ of TB patients in block-1 and $38 \%$ in block- 2 were found in the TB score SC-III. After 4 months, progressive change was observed in TB score of block-1 (mean \pm SD of $2.6 \pm 1.8 ; 95 \%$ $\mathrm{CI}$ of 1.95 to $3.17 ; \mathrm{p}<0.001$ ) as compared to block-2 (mean \pm $\mathrm{SD}$ of $6.7 \pm 1.8 ; 95 \% \mathrm{CI}$ of 6.13 to $7.37 ; \mathrm{p}=0.21$ ). The number of TB patients with TB score SC-I was significantly improved by $56.3 \%$ in block- 1 , but this improvement was very small in block-2 (only 3.1\%) (Table 3). Holding location, occupation, and family size constant, there was an inverse relationship between TB score and serum 25(OH)D levels in block-1 $(\beta=$ $0.630, p<0.001)$. About $33 \%$ of the variability of TB score in block-1 was accounted for by the change in the serum $25(\mathrm{OH})$ $\mathrm{D}$ level. However, the contribution of the change in $25(\mathrm{OH}) \mathrm{D}$ level for such variability in block-2 was $22 \%$. 
Table 1: Basic Characteristics of TB patients assigned in block-1 and -2

\begin{tabular}{|c|c|c|c|c|}
\hline Variables & & Block-1 & Block-2 & p-value \\
\hline Age (years) median (IQR) & Age & $28(14)$ & $26(8.5)$ & 0.90 \\
\hline $\operatorname{Sex} n(\%)$ & Male & $18(56.3)$ & $16(50.0)$ & 0.62 \\
\hline Location n (\%) & Urban & $21(65.6)$ & $20(62.5)$ & 0.79 \\
\hline \multirow[t]{5}{*}{ Educational Status n (\%) } & Illiterate & $2(6.3)$ & $3(9.4)$ & 0.43 \\
\hline & Primary Education & $11(34.4)$ & $15(46.9)$ & \\
\hline & Secondary Education & $14(43.7)$ & $13(40.6)$ & \\
\hline & Tertiary Education & $3(9.4)$ & $1(3.1)$ & \\
\hline & Religious Education & $2(6.2)$ & $0(0.0)$ & \\
\hline \multirow[t]{5}{*}{ Occupation n (\%) } & Student & $7(21.9)$ & $6(18.7)$ & 0.79 \\
\hline & Farmer & $6(18.7)$ & $6(18.7)$ & \\
\hline & Working for the government & $6(18.8)$ & $10(31.3)$ & \\
\hline & Working for NGO* & $9(28.1)$ & $6(18.8)$ & \\
\hline & House Wife & $4(12.5)$ & $4(12.5)$ & \\
\hline \multirow[t]{2}{*}{ Marital Status n (\%) } & Single & $17(53.1)$ & $11(34.4)$ & 0.13 \\
\hline & Married & $15(46.9)$ & $21(65.6)$ & \\
\hline \multirow{3}{*}{ Family Size n (\%) } & 1 to 4 & $12(37.5)$ & $5(15.6)$ & 0.12 \\
\hline & 5 to 8 & $15(46.9)$ & $22(68.8)$ & \\
\hline & $>8$ & $5(15.6)$ & $5(15.6)$ & \\
\hline \multirow[t]{4}{*}{ Monthly Income n (\%) } & $\leq 1000 \mathrm{ETB}^{*}$ & $3(9.4)$ & $10(31.3)$ & 0.11 \\
\hline & 1001 to $3000 \mathrm{ETB}^{*}$ & $20(62.5)$ & $12(37.5)$ & \\
\hline & 3001 to $5000 \mathrm{ETB}^{*}$ & $6(18.7)$ & $6(18.7)$ & \\
\hline & $>5000 \mathrm{ETB}^{*}$ & $3(9.4)$ & $4(12.5)$ & \\
\hline \multirow[t]{4}{*}{ Money spent for food n (\%) } & 30 to $40 \%$ of monthly income & $16(50.0)$ & $7(21.9)$ & 0.072 \\
\hline & 40.1 to $50 \%$ of monthly income & $7(21.9)$ & $14(43.7)$ & \\
\hline & 50.1 to $60 \%$ of monthly income & $5(15.6)$ & $4(12.5)$ & \\
\hline & $>60 \%$ of monthly income & $4(12.5)$ & $7(21.9)$ & \\
\hline \multirow{2}{*}{ Working in the Sun for 1 hour/day n $(\%)$} & No & $12(37.5)$ & $18(56.3)$ & 0.13 \\
\hline & Yes & $20(62.5)$ & $14(43.7)$ & \\
\hline \multirow{2}{*}{ Clothing style (covering the body) n (\%) } & No & $5(15.6)$ & $10(31.3)$ & 0.14 \\
\hline & Yes & $27(84.4)$ & $22(68.7)$ & \\
\hline \multirow[t]{2}{*}{ Use of sun protection $n(\%)$} & No & $7(21.9)$ & $10(31.3)$ & 0.39 \\
\hline & Yes & $25(78.1)$ & $22(68.7)$ & \\
\hline \multirow{2}{*}{$\begin{array}{l}\text { Vitamin D-rich food consumption (E.g. } \\
\text { Oily Fish) n (\%) }\end{array}$} & No & $24(75.0)$ & $25(78.1)$ & 0.77 \\
\hline & Yes & $8(25.0)$ & $7(21.9)$ & \\
\hline AFB Smear Examination n (\%) & AFB Smear $\geq 3+$ & $24(75.0)$ & $31(96.9)$ & 0.012 \\
\hline BMI mean (SD) & BMI & $17.5(2.4)$ & $18.7(3.8)$ & 0.13 \\
\hline MUAC median (IQR) & MUAC & $21(5)$ & $20(3)$ & 0.93 \\
\hline
\end{tabular}

Table 2: Serum 25(OH) vitamin D status of TB patients in block-1 and -2 before and after consuming the sandwich bread

\begin{tabular}{|l|c|c|c|c|c|c|}
\hline Categories of 25(OH)Vitamin D Status & \multicolumn{2}{|c|}{ Block-1 } & & \multicolumn{2}{c|}{ Block-2 } & \\
\hline & Beforen (\%) & Aftern (\%) & p - value & Beforen (\%) & Aftern (\%) & p - value \\
\hline SVDD $\ddagger$ & - & - & $\mathbf{0 . 0 0 1 2}$ & $1(3.4)$ & $1(3.4)$ & 0.73 \\
\hline VDD§ & $13(41.9)$ & $2(6.4)$ & & $12(41.4)$ & $7(24.1)$ & \\
\hline VDI $\dagger$ & $18(58.1)$ & $8(25.8)$ & & $17(58.6)$ & $15(51.7)$ & \\
\hline Sufficient VD; & $13(41.9)$ & $23(74.2)$ & & $12(41.4)$ & $14(48.3)$ & \\
\hline
\end{tabular}

\$sVDD - Severe Vitamin D Deficiency $(\leq 10 \mathrm{ng} / \mathrm{mL}) ; \S$ VDD - Vitamin D Deficiency $(\leq 20 \mathrm{ng} / \mathrm{mL}), \dagger$ VDI - VitaminD Insufficiency $(\leq 30 \mathrm{ng} / \mathrm{mL})$, and $;$ Sufficient VD - Sufficient Vitamin D $(>30 \mathrm{ng} / \mathrm{mL})$ 

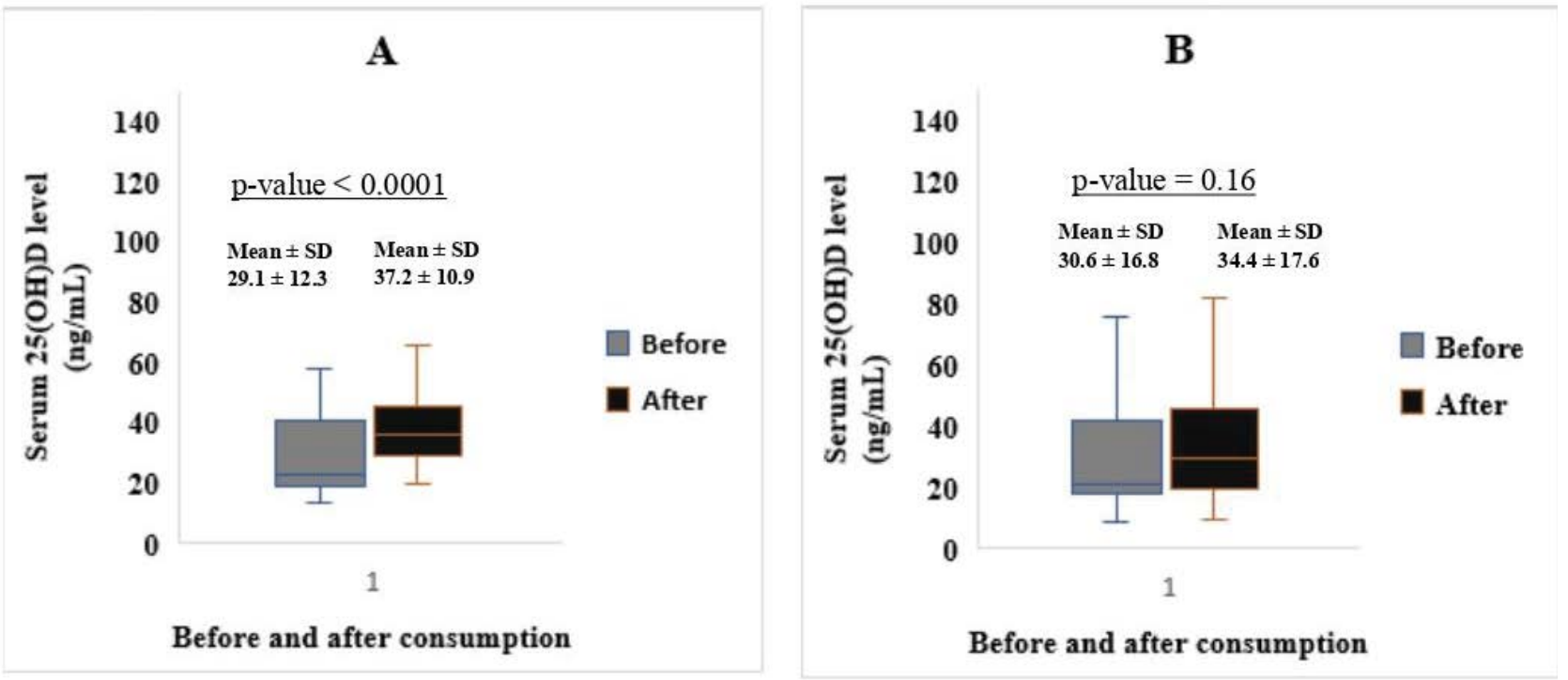

Figure 1: Changes in serum 23(OH)Dlevel of TB patients before and after consuming the sandwich bread. Significant change was observed in block-1 (A) but not in block-2 (B).

Table 3: Clinical and laboratory findings in block-1 and -2

\begin{tabular}{|c|c|c|c|c|c|c|}
\hline \multirow[t]{2}{*}{ Variables } & \multicolumn{2}{|c|}{ Block-1 } & \multirow[b]{2}{*}{ p-value } & \multicolumn{2}{|c|}{ Block-2 } & \multirow[b]{2}{*}{ p-value } \\
\hline & $\begin{array}{c}\text { Before } \\
\text { n (\%) }\end{array}$ & $\begin{array}{l}\text { After } \\
\text { n (\%) }\end{array}$ & & $\begin{array}{c}\text { Before } \\
\text { n (\%) }\end{array}$ & $\begin{array}{l}\text { After } \\
\text { n (\%) }\end{array}$ & \\
\hline \multicolumn{7}{|l|}{ TB Score Severity Class (SC) } \\
\hline SC-I (0 to 5 Points) & $13(40.6)$ & $31(96.9)$ & $<0.001$ & $8(25.0)$ & $7(21.9)$ & 0.88 \\
\hline SC-II (6 to 7 Points) & $8(25.0)$ & $1(3.1)$ & & $12(37.5)$ & $14(43.7)$ & \\
\hline SC- III ( 8 Points) & $11(34.4)$ & $0(0.0)$ & & $12(37.5)$ & $11(34.4)$ & \\
\hline \multicolumn{7}{|l|}{ Karnofsky performance status scale } \\
\hline 50 Points & $5(15.6)$ & $0(0)$ & $<0.001$ & $1(3.1)$ & $0(0.0)$ & 0.52 \\
\hline 60 Points & $16(50.0)$ & $0(0)$ & & $15(46.9)$ & $13(40.6)$ & \\
\hline 70 Points & $11(34.4)$ & $7(21.9)$ & & $16(50.0)$ & $18(56.3)$ & \\
\hline$\geq 80$ Points & $0(0.0)$ & $25(78.1)$ & & $0(0.0)$ & $1(3.1)$ & \\
\hline \multicolumn{7}{|l|}{ Acid Fast Bacilli (AFB) $\dagger$} \\
\hline Smear $+1, \mathrm{n}(\%)$ & $0(0)$ & $10(31.3)$ & $<0.001$ & $0(0.0)$ & $14(43.7)$ & $<0.001$ \\
\hline Smear $+2, \mathrm{n}(\%)$ & $8(25.0)$ & $14(43.7)$ & & $1(3.1)$ & $15(46.9)$ & \\
\hline Smear $+3, \mathrm{n}(\%)$ & $16(50.0)$ & $5(15.6)$ & & $21(65.6)$ & $1(3.1)$ & \\
\hline Smear $+4, \mathrm{n}(\%)$ & $8(25.0)$ & $3(9.4)$ & & $10(31.3)$ & $2(6.3)$ & \\
\hline
\end{tabular}

TB score had statistically significant inverse correlation with Karnofsky performance status scale $(\mathrm{r}=-0.554, \mathrm{p}=<0.001)$, body weight $(\mathrm{r}=-0.393, \mathrm{p}=0.001)$, BMI $(\mathrm{r}=-0.498, \mathrm{p}<0.001)$, and MUAC $(r=-0.515, p<0.001)$. The mean \pm SD of Karnofsky performance status scale before and after consumption were 61.9 $\pm 6.9 \%$ and $80.3 \pm 6.9 \%$ in block- 1 , and $64.7 \pm 5.7 \%$ and 66.2 $\pm 5.5 \%$ in block-2, respectively. The change in the Karnofsky performance status scale was statistically significant in block-1 $(\mathrm{p}<0.001)$, but not in block-2 $(\mathrm{p}=0.52)($ Table 3$)$. There was a strong correlation between BMI and MUAC $(r=0.71, p<0.001)$. After 4 months, block-1 had significant improvements in BMI (by $0.91 \mathrm{~kg} / \mathrm{m}^{2}$ ) and MUAC (by $1.16 \mathrm{~cm}$ ). However, these improvements were not statistically significant in block-2 (BMI by $-0.01 \mathrm{~kg} / \mathrm{m}^{2}$ and MUAC by $\left.-0.1 \mathrm{~cm}\right)$. 


\section{Laboratory outcomes}

AFB smear examinations and bacterial culture were performed to analyze the changes in the bacterial load. After 4 months, both blocks had significant changes in AFB load ( $p<0.001$ ), in which more than $30 \%$ of TB patients had AFB smear examination level +1 ( 1 to 9 AFB observed/ 100 high powered fields). Despite the changes in the bacterial load, total AFB smear negativity could not be achieved and most of the patients were culture positive. In both blocks, the changes in the culture conversion were not statistically significant (Table 3 ).

Table 4 illustrates the changes in cytokines and cathelicidin (LL-37) levels before and after consumption. There were significant changes in the means of IFN- $\gamma$ and LL-37 $(p<0.05)$ levels in block-1, but not in block-2. IFN- $\gamma$ had significant positive correlation with $25(\mathrm{OH}) \mathrm{D}(\mathrm{r}=0.426, \mathrm{p}=0.017)$. The levels of IFN- $\gamma(\beta=0.349, p=0.039)$ and LL-37 $(\beta=0.366$, $\mathrm{p}=0.0 .028)$ had significant relationship with $25(\mathrm{OH}) \mathrm{D}$ level holding location, occupation and family size constant. In both blocks, the difference in the level of CRP was not significant.

\section{DISCUSSION}

We demonstrated for the first time the role of consuming sunexposed oyster mushroom on the treatment outcomes of TB. A high proportion $(\geq 40 \%)$ of VDD was found in this study and it was directly related to factors such as lack of Sun-exposure and inadequate intake of vitamin D-rich diets. These two factors were identified together with others in our previous systematic review as the main predictor variables of vitamin D status among TB patients in Africa [18].

Consuming vitamin $\mathrm{D}_{2}$ enriched oyster mushrooms brought a significant difference of $8.1 \mathrm{ng} / \mathrm{mL}$ in the mean $25(\mathrm{OH}) \mathrm{D}$ level and corrected the deficiency in more than $35 \%$ of TB patients without showing any adverse effects. Urbain et al. [25] demonstrated that intervention with vitamin $\mathrm{D}_{2}$-enhanced button mushrooms via UVB irradiation was effective in improving vitamin D status. Comparable to our study, Yesudian et al. [26] found a $9.16 \mathrm{ng} / \mathrm{mL}$ increase in the mean 25(OH)D level from a baseline of $11.23 \mathrm{ng} / \mathrm{mL}$ in 3 consecutive days of
UVB exposure to Asian immigrants in the UK. Tukvadze et al. [20] in Georgia also showed that adjunctive high-dose oral vitamin $\mathrm{D}_{3}$ was safe and led to a substantial increase in plasma 25(OH)D concentrations over 16 weeks.

A previous study revealed that oral vitamin D supplementation was associated with significant suppression of the concentrations of circulating inflammatory markers, like CRP [27]. In this study, there was no significant change in the level of CRP. Similarly, Wu et al. [28] confirmed that there was no evidence of the improvement of CRP after the intervention. Our previous work underscored that CRP was not the best option to control the change in the acute phase response of micronutrient levels in the serum of TB patients [29].

Intriguingly, consumption of the sandwich bread ameliorated the clinical outcomes and immune responses of TB patients, but not sputum culture conversion. Clinical outcomes were assessed by TB score and Karnofsky performance status scale. Wejse et al. [23] found that TB score declined for $96 \%$ of the surviving patients from initiation to end of treatment. At the end of standard chemotherapy at 6 months, most patients had a TB score below 1 [30].

In this study, a progressive change was observed during 4 months of consumption in block-1. Most patients (96.9\%) found in TB score SC-I, having more than 55\% improvement from baseline. During the same duration of treatment, about $22 \%$ of patients in block- 2 were found in TB score SC-I with less than $5 \%$ improvement. There was a significant inverse relationship between TB score and serum $25(\mathrm{OH}) \mathrm{D}$ level. The variability of TB score in more than one-third of TB patients was attributed to the change in the serum $25(\mathrm{OH}) \mathrm{D}$ level. In line with this, a study done in Iran indicated a reduction of TB score in patients who took a single oral dose of 450,000 IU cholecalciferol after 2 and 3 months of treatment [31]. Another study done in Egypt showed better healing after 1000 IUs of oral vitamin D supplementation [32]. More recently, Bekele and his colleagues [30] reported that an additional $25 \%$ reduction in the TB score in the intervention group was considered as a significant effect.

Table 4: Changes in the serum cytokines and cathelicidin LL-37 levels in block-1 and -2.

\begin{tabular}{|l|c|c|c|c|c|c|}
\hline Cytokines $(\mathbf{p g} / \mathbf{m L})$ & \multicolumn{2}{|c|}{ Block-1 (Mean \pm SD) } & p-value & \multicolumn{2}{c|}{ Block-2 (Mean \pm SD) } & p-value \\
\hline & Before & After & & Before & After & \\
\hline IFN-g & $14.9 \pm 12.2$ & $59.5 \pm 39.8$ & $\mathbf{0 . 0 1 *}$ & $13.8 \pm 7.0$ & $14.8 \pm 8.7$ & 0.69 \\
\hline IL-4 & $4.6 \pm 3.4$ & $6.5 \pm 5.0$ & 0.73 & $9.8 \pm 10.4$ & $9.0 \pm 8.2$ & 0.34 \\
\hline IL-10 & $15.2 \pm 5.8$ & $17.8 \pm 5.9$ & 0.44 & $20.3 \pm 8.8$ & $14.6 \pm 5.6$ & 0.26 \\
\hline Anti-microbial peptide (ng/mL) & & $165.9 \pm 92.7$ & $174.8 \pm 90.1$ & 0.21 \\
\hline Cathelicidin LL-37 & $192.7 \pm 65.2$ & $245.3 \pm 99.3$ & $\mathbf{0 . 0 2 *}$ & \\
\hline
\end{tabular}


TB score was inversely associated with the Karnofsky performance status scale. In this study, there was a significant change in the Karnofsky performance status scale in block-1 having a mean of $80.3 \%$ as compared to $66.2 \%$ in block- 2 . Similarly, there was a significant change in nutritional status as assessed by BMI and MUAC. BMI had a strong relationship with MUAC. We observed the improvements of BMI (by $0.91 \mathrm{~kg} / \mathrm{m}^{2}$ ) and MUAC (by $1.16 \mathrm{~cm}$ ) solely in block-1. In agreement with this, Salahuddin et al. [33] showed that 2 doses of 600,000 IU vitamin D administered intramuscularly resulted in a greater weight gain by $1.14 \mathrm{~kg}$ and improvement in BMI. Two small randomized studies $[32,34]$ have also suggested the beneficial effects of vitamin D on weight gain. These implied that the improvement in the level of vitamin D has a contribution to the improvement of the nutritional status of TB patients.

Regarding bacterial load, we could not find a whole AFB smear negativity and sputum culture conversion. Comparable to this, several studies done elsewhere $[30,33,35,36]$ demonstrated that vitamin D supplementation did not affect the time to sputum smear and culture conversion. However, there were some contrasting reports. Studies done by Nursyam et al. [34] and Coussens et al. [37] indicated that vitamin D supplementation accelerated sputum smear conversion. Martineau et al. [38] also showed that administration of four doses of $2.5 \mathrm{mg}$ vitamin $\mathrm{D}_{3}$ had a faster effect on sputum smear conversion in patients with the tt genotype of the TaqI VDR polymorphism. Therefore, the reasons for such inconsistencies could be the presence of the variants of VDR polymorphisms, variability in vitamin $D$ dosages, or different phases of baseline serum 25(OH)D level as indicated in Farazi et al. [31].

Vitamin D is implicated in the induction of IFN- $\gamma$ mediated activity in macrophages [39]. In this study, a significant increase in IFN- $\gamma$ level but not IL-4 and IL-10 levels were found in block-1. In agreement with our study, Salahuddin et al. [33] showed that vitamin D administration brought significant change in IFN- $\gamma$ production in TB patients with VDD at baseline. In vitro study also indicated that supplementation of vitamin D deficient serum with $25(\mathrm{OH}) \mathrm{D}_{3}$ restored IFN- $\gamma$ [39]. However, some studies reported that vitamin D intervention inhibits the level of IFN- $\gamma$, but enhances the production of IL4, and IL-10 [40-42]. These recapped that the difference in the effects of vitamin D intervention on the levels of cytokines was mainly dependent on VDD at baseline.

In the present study, there was a significant change in the level of cathelicidin LL-37 in block-1. This was supported by several studies done elsewhere [20, 40, 41, 43, 44]. We found a direct relationship between LL-37, IFN- $\gamma$, and 25(OH)D levels in block-1. This indicated that better status of vitamin D increases the level of IFN- $\gamma$ mediated cathelicidin LL-37. According to different studies, vitamin $\mathrm{D}$ promotes mycobacterial killing [44] or reduced intracellular viability of M. tuberculosis [27] in macrophages through the production of cathelicidin LL-37, after activation of macrophages via toll-like receptor [45] or IFN- $\gamma$ pathways [39].

\section{LIMITATION}

We did not analyze the nutrient contents of oyster mushrooms except vitamin D. Data on the genotypes of VDR polymorphisms were not included as we could not have access to measure the genes of VDR polymorphisms at the time of the study. VDR polymorphisms are, however, expected to influence the effects of vitamin D intervention.

\section{CONCLUSION}

In conclusion, consumption of sun-exposed oyster mushrooms effectively corrected VDD in TB patients without showing any adverse reaction. The accelerated improvements on the clinical and immunological outcomes, although not on sputum smear conversion, give us a clue that sun-exposed oyster mushrooms could serve as potential, safe, easily available, and affordable adjunctive treatment and helps patients fight TB. As this is the first study, further investigations on the interactions of vitamin $\mathrm{D}_{2}$, sputum smear conversion, and immunological responses on the large size and diverse groups of TB patients are warranted.

\section{ACKNOWLEDGEMENT}

This study was financially supported by Dr.Hermann Eiselen Ph.D. Grant from the Foundation fiat panis. The first author obtained a scholarship from the Food Security Centre of the University of Hohenheim, which is supported by the German Academic Exchange Service (DAAD) with funds from the Federal Ministry of Economic Cooperation and Development (BMZ) of Germany. We acknowledge all TB patients and health professionals who participated in this study. We are thankful to the health bureau of North Shewa Zone of Amhara Regional State, Debre Birhan Referral Hospital, Health Centres, Debre Birhan University, and AHRI for their cooperation. We are also grateful to Alexandar Koza (University of Hohenheim, Germany), Solomon Tadesse (Debre Birhan University, Ethiopia), Mulu Zegeye (Bio-Enguday Production and Sale Micro-Enterprise, Ethiopia) and, Azeb Tadesse and Emawayish Andargie (AHRI, Ethiopia) for their unreserved technical assistances. Drs. Adane Mihret and Markos Abebe are also acknowledged to their great contribution for the success of this study. 


\section{STATEMENT OF AUTHORSHIP}

TSK and HKB conceived and designed the experiments; TSK performed the experiments, analyzed the samples, collected, analysed, and interpreted the data, and wrote the manuscript; and AS, AZW, CL, DN, and HKB critically reviewed and approved the manuscript.

\section{CONFLICT OF INTEREST STATEMENT}

The authors declare no conflict of interest.

\section{FUNDING}

This research did not receive any specific grant from funding agencies in the public, commercial, or non-profit organization.

\section{REFERENCES}

1. WHO (2014) World Health Organization c1948. Tuberculosis fact sheet Geneva (Switzerland): WHO global TB programme. Available from: http://www.who.int/mediacentre/factsheets/fs104/en/

2. Comas I, Gagneux S (2009) The past and future of tuberculosis research. PLoS Pathog; 5 (10): p. e1000600 Available from: http://www.plospathogens.org/article/ info\%3Adoi\%2F10.1371\%2Fjournal.ppat. 1000600

3. Fogel N (2015) Tuberculosis: A disease without boundaries. Tuberc; 95:527e531

4. Keshavjee S, Farmer P (2012) Tuberculosis, drug, resistance, and the history of modern medicine. N Engl J Med; 367 (10): 931-936. Available from: http://www.nejm.org/doi/full/10.1056/ NEJMra1205429

5. Goldman L, Schafer AI (2011) Tuberculosis: disease overview L. Goldman, A.I. Schafer (Eds.), Goldman's cecil medicine: expert consult premium edition (24th ed.), Saunders Elsevier, St. Louis (MO).

6. Nnoaham KE, Clarke A (2008) Low serum vitamin D levels and tuberculosis: a systematic review and meta- analysis. Int $\mathrm{J}$ Epidemiol; 37:113-9.

7. Williams C (1849) Cod liver oil in phthisis. Lond J Med;1: 1-18.

8. Martineau AR (2012) Old wine in new bottles: vitamin D in the treatment and prevention of tuberculosis. Proc Nutr Soc; 71:84-9.

9. Valverde ME, T. Hernández-Pérez O (2015) Paredes-López Edible mushrooms: improving human health and promoting quality life: review. Int. J. Microbiol; 1-14.

10. Chen TC, Lu Z, Holick MF (2010) Photobiology of vitamin D. MF. Holick (Ed.), Vitamin D Physiology, Molecular Biology, and Clinical Applications from Nutrition and Health, Springer Science and Business Media.

11. Keegan RJH, Lu Z, Bogusz JM, Williams JE, Holick MF (2013) Photobiology of vitamin D in mushrooms and its bioavailability in humans Dermatoendocrinology; 5 (1): 165-176

12. Mattila P, Konko K, Eurola M, Pihlava JM, Astola J, et al. (2001) Contents of vitamins, mineral elements, and some phenolic com pounds in cultivated mushrooms. J. Agric. Food Chem; 49: 2343-2348. doi: 10.1021/jf001525d.
13. Teichmann A, Dutta PC, Staffas A, Jägerstad M (2007) Sterol and vita_min $\mathrm{D}_{2}$ concentrations in cultivated and wild grown mushrooms: effects of UV irradiation. LWT Food Sci. Technol; 40: 815-822. doi: 10.1016/j.lwt.2006.04.003

14. Mau JL, Chen PR, Yang JH (1998) Ultraviolet irradiation increased vitamin $\mathrm{D}_{2}$ content in edible mushrooms. J. Agric. Food Chem; 46: 5269-5272. doi: 10.1021/jf980602q

15. Roberts JS, Teichert A, McHugh TH (2008) Vitamin $\mathrm{D}_{2}$ formation from post-harvest UV-B treatment of mushrooms (Agaricus bisporus) and retention during storage. J Agric Food Chem; 56(12): 4541 - 4. doi: 10.1021/jf0732511. Epub.

16. Keflie TS, Nölle N, Lambert C, Nohr D, Biesalski HK (2019) Impact of the natural resource of UVB on the content of vitamin $\mathrm{D}_{2}$ in oyster mushroom (Pleurotus ostreatus) under subtropical settings. Saudi J. Biol. Sci; 26 (7): 1724-1730.

17. Holick MF, Garabedian M (2006) Vitamin D: photobiology, metabolism, mechanisms of action, and clinical applications. In: Favus MJ, editor. Primer on the metabolic bone diseases and mineral metabolism. Chicago: ASBMR; 106-14.

18. Keflie TS, Nölle N, Lambert C, Nohr D, Biesalski HK (2015) Vitamin D deficiencies among tuberculosis patients in Africa: A systematic review. Nutrition; 31: 1204-1212.

19. Keflie TS, Ameni G (2014) Microscopic examination and smear negative pulmonary tuberculosis in Ethiopia. Pan Afr Med J; 19:162. http://dx.doi.org/10.11604/pamj.2014.19.162.3658.

20. Tukvadze N, Sanikidze E, Kipiani M, Hebbar G, Easley KA, et al. (2015) High-dose vitamin D3 in adults with pulmonary tuberculosis: a double-blind randomized controlled trial. Am J Clin Nutr; 102:1059-69.

21. EFMACA (2014) Food, Medicine and healthcare administration and control authority of Ethiopia. Standard treatment guidelines for general hospital. Third edition, Addis Abeba, Ethiopia.

22. FANTA III (2013) Food and nutrition technical assistance. use of cut-offs for mid-upper arm circumference (MUAC) as an indicator or predictor of nutritional and health related outcomes. Adolescents and adults: a systematic review. FHI 3601825 Connecticut Avenue, NW.

23. Wejse C, Gustafson P, Nielsen J, Gomes VF, Aaby P, et al. (2008) A clinical score system for monitoring tuberculosis in a lowresource setting. Scand J Infect Dis; 40:111-120.

24. Karnofsky DA, Burchenal JH (1949) The clinical evaluation of chemotherapeutic agents in cancer. In: MacLeod CM, eds. Evaluation of chemotherapeutic agents. New York: Columbia University Press; 191-205.

25. Urbain P, Singler F, Ihorst G, Biesalski HK, Bertz H (2011) Bioavailability of vitamin $\mathrm{D}_{2}$ from UV-B- irradiated button mushrooms in healthy adults deficient in serum 25-hydroxyvitamin D: a randomized controlled trial. Eur J Clin Nutr; 65: 965-971.

26. Yesudian PD, Berry JL, Wiles S, Hoyle S, Young DB, et al. (2008) The effect of ultraviolet B-induced vitamin D levels on host resistance to Mycobacterium tuberculosis: a pilot study in immigrant Asian adults living in the United Kingdom. Photodermatology, Photoimmunology \& Photomedicine; 24: 97-98. 
27. Kibirige D, Kiggundu DS, Worodria W (2013) What is the link between vitamin D and tuberculosis? South Afr J Epidemiol Infect; 28(4): 192-196.

28. Wu H, Xiong X, Zhu M, Wei J, Zhuo K (2018) Effects of vitamin D supplementation on the outcomes of patients with pulmonary tuberculosis: a systematic review and meta-analysis. $B M C$ Pulmonary Medicine; 18: 108. https://doi.org/10.1186/s12890018-0677-6

29. Keflie TS, Samuel A, Woldegiorgis AZ, Mihret A, Abebe M, et al. (2018) Vitamin A and zinc deficiencies among tuberculosis patients in Ethiopia. J Clin Tuberc Other Mycobact Dis; 12: 27-33.

30. Bekele A, Gebreselassie N, Ashenafi S, Kassa E, Aseffa G, et al. (2018) Daily adjunctive therapy with vitamin D3 and phenylbutyrate supports clinical recovery from pulmonary tuberculosis: a randomized controlled trial in Ethiopia. J Intern Med. doi: 10.1111/joim.12767.

31. Farazi A, Didgar F, Sarafraz A (2017) The effect of vitamin D on clinical outcomes in tuberculosis. Egypt J Chest Dis Tuberc; 66: 419-423.

32. Morcos MM, Gabr AA, Samuel S, Kamel M, el Baz M, et al. (1998) Vitamin D administration to tuberculous children and its value. Bolletino Chimico Farmaceutico; 137:157-164.

33. Salahuddin N, Ali F, Hasan Z, Rao N, Aqeel M, et al. (2013) Vitamin $\mathrm{D}$ accelerates clinical recovery from tuberculosis: results of the SUCCINCT Study [Supplementary Cholecalciferol in recovery from tuberculosis]. A randomized, placebo-controlled, clinical trial of vitamin D supplementation in patients with pulmonary tuberculosis ${ }^{\text {ee }}$. BMC Infect Dis; 13:22.

34. Nursyam EW, Amin Z, Rumende CM (2006) The effect of vitamin $\mathrm{D}$ as supplementary treatment in patients with moderately advanced pulmonary tuberculous lesion. Acta Medica Indonesiana; 38: 3-5.

35. Daley P, Jagannathan V, John KR, Sarojini J, Latha A, et al. (2015) Adjunctive vitamin D for treatment of active tuberculosis in India: a randomised, double-blind, placebo-controlled trial, Lancet Infect Dis; 15(5): 528-534.

36. Wejse C, Gomes VF, Rabna P, Gustafson P, Aaby P, et al. (2009) Vitamin D as supplementary treatment for tuberculosis: a doubleblind, randomized, placebo-controlled trial. American Journal of Respiratory Critical Care Medicin; 179: 843-50.
37. Coussens AK, Wilkinson RJ, Hanifa Y, Nikolayevskyy V, Elkington PT, Islam K, et al. Vitamin D accelerates resolution of inflammatory responses during tuberculosis treatment. PNAS U S A. 2012 ; 109: 15449-15454.

38. Martineau AR, Timms PM, Bothamley GH, Hanifa Y, Islam $K$, et al. (2011) High-dose vitamin $D_{3}$ during intensive-phase antimicrobial treatment of pulmonary tuberculosis: a doubleblind randomised controlled trial. Lancet; 377: 242-50.

39. Fabri M, Stenger S, Shin DM, Yuk JM, Liu PT, et al. (2011) Vitamin D is required for IFN-gamma- mediated antimicrobial activity of human macrophages. Sci Transl Med; 3: 104ra102. doi:10.1126/scitranslmed.3003045.

40. Khoo A, Chai LYA, Koenen HJPM, Oosting M, Steinmeyer A, et al. (2011) Vitamin $D_{3}$ down- regulates proinflammatory cytokine response to Mycobacterium tuberculosis through pattern recognition receptors while inducing protective cathelicidin production. Cytokine; 55: 294-300.

41. Rode AKO, Kongsbak M, Hansen MM, Lopez DV, Levring TB, et al. (2017) Vitamin D Counteracts Mycobacterium tuberculosis-Induced Cathelicidin Downregulation in Dendritic Cells and Allows Th1 Differentiation and IFN $\gamma$ Secretion. Front Immunology; 8: 656. doi: 10.3389/fimmu.2017.00656.

42. Vidyarani M, Selvaraj P, Jawahar MS, Narayanan PR (2007) 1, 25 Dihydroxyvitamin $\mathrm{D}_{3}$ modulated cytokine response in pulmonary tuberculosis. Cytokine; 40: 128 - 134.

43. Mily A, Rekha RS, Kamal SMM, Arifuzzaman ASM, Rahim Z, et al. (2015) Significant Effects of Oral Phenylbutyrate and Vitamin D3 Adjunctive Therapy in Pulmonary Tuberculosis: A Randomized Controlled Trial. PLoS ONE; 10(9): e0138340. doi:10.1371/journal.pone. 0138340 .

44. Ralph AP, Waramori G, Pontororing GJ, Kenangalem E, Wiguna A, et al. (2013) L-arginine and Vitamin D Adjunctive Therapies in Pulmonary Tuberculosis: A Randomised, Double-Blind, PlaceboControlled Trial. PLOS ONE; 8(8): e70032. doi:10.1371/journal. pone.0070032.

45. Liu PT, Stenger S, Li H, Wenzel L, Tan BH, et al. (2006) Toll-like receptor triggering of a vitamin D mediated human antimicrobial response. Science; 311(5768): 1770-1773. https:// doi.org/10.1126/science. 1123933 